\title{
LA EXIGENCIA DE ESPIRITUALIDAD UN SIGNO DE LOS TIEMPOS*
}

Autor: Antonio Bravo Tisner. Sacerdote del Prado, de la archidiócesis de Madrid.

Los sacerdotes necesitan renovación, ser hombres de interioridad, de oración que ayuden al hombre secular a volver a la casa del Padre. Juan de Ávila tomó este camino para su tiempo.

DOI: https://doi.org/10.52039 seminarios.v49i168.824

Partiendo de un texto de la Carta Apostólica de Juan Pablo II, Novo Millennio Ineunte, y en el marco de la fiesta de san Juan de Ávila, me propongo abordar estas tres cuestiones: ¿Qué nuevos motivos existen hoy para afirmar que el clero estamos necesitados de una espiritualidad? ¿Qué espiritualidad debe desarrollarse entre nosotros? ¿Qué medios darnos?

\section{I.- NECESIDAD DE UNA ESPIRITUALIDAD}

¿No es acaso un "”signo de los tiempos" el que hoy, a pesar de los vastos procesos de secularización, se detecte una difusa exigencia

* Conferencia pronunciada ante el Presbiterio de la Archidiócesis de Madrid, el día 10-V-2002. Fiesta del Santo Maestro Juan de Ávila. 
de espiritualidad, que en gran parte se manifiesta precisamente en una renovada necesidad de orar? También las otras religiones, ya presentes extensamente en los territorios de antigua Cristianización, ofrecen sus propias respuestas a esta necesidad, y lo hacen a veces de manera atractiva. Nosotros, que tenemos la gracia de creer en Cristo, revelador del Padre y Salvador del mundo, debemos enseñar a qué grado de interiorización nos puede llevar la relación con él (TMI 33).

Insistir en la urgencia y exigencia de una espiritualidad para el clero, no tiene nada de nuevo. Hoy seguimos escuchando el eco de los profetas contra los sacerdotes infieles a Dios y al pueblo elegido. Los escritos del Nuevo Testamento recalcan que el apóstol es, ante todo, un discípulo.

Las crisis y las grandes reformas, vividas en el curso de la historia por la Iglesia, están estrechamente ligadas a la renovación espiritual del clero. Como testigo, baste evocar a san Juan de Ávila.

Los motivos de esta urgencia, sin embargo, varían mucho en el transcurso de los siglos, aun cuando todos apunten a desarrollar la vocación a la santidad que comporta el don del ministerio sacerdotal o apostólico. En la etapa martirial de la Iglesia, por ejemplo, la espiritualidad se presenta como una exigencia indispensable para permanecer firmes en el testimonio. Diferentes son las motivaciones en los aledaños del Concilio de Trento. La cristiandad necesita sacerdotes dignos, que vivan de acuerdo con el sacramento de la Eucaristía y con el oficio de confesar y de instruir al Pueblo de Dios.

En al fondo de todas las motivaciones, resuenan siempre las palabras de Pablo dirigidas en Mileto a los presbíteros de Éfeso: "Tened cuidado de vosotros y de toda la grey, en medio de la cual os ha puesto el Espíritu Santo como vigilantes para pastorear la Iglesia de Dios, que él se adquirió con la sangre de su propio Hijo” (Hech 20, 28). Ministerio pastoral y exigencia radical de santidad están intrínsecamente unidos. Nadie puede producir frutos abundantes y duraderos sin estar unido a Cristo y sin una profunda vida de oración.

Preguntémonos ahora por los motivos que reclaman de nosotros con urgencia una intensa vida espiritual, en este mundo que solemos caracterizar con términos como secularizado, plural, democrático y globalizado. 


\section{Añoranza de transcendencia en el hombre de hoy}

Si en el corazón de nuestros contemporáneos hay, como señala el Papa, una difusa exigencia de espiritualidad y una renovada necesidad de orar, mal podríamos sintonizar los sacerdotes con el corazón de nuestro mundo, si no fuéramos hombres de interioridad, testigos de la Palabra y verdaderos maestros de la experiencia de Dios.

Los signos de los tiempos se presentan como un reto para la vida y misión de la Iglesia, en particular para sus pastores. Debemos escrutarlos y discernirlos para descubrir hacia dónde el Espíritu encamina a la humanidad y cómo colaborar activamente con él. Pero esto no puede hacerse sin que la persona en su totalidad se halle implicada. La búsqueda de espiritualidad no se contrapone a la acción, antes bien es el motor de toda actividad apostólica.

La humanidad no deja de progresar, aunque no siempre de forma lineal. Cuando los cambios y mutaciones son acelerados, la palabra crisis hace su aparición; y, como lo recuerda la historia de pueblos y culturas, se replantea la misión de la filosofía, de las religiones y también de la Iglesia en el mundo.

Hombre formado en la historia, Juan XXIII, en la Constitución Apostólica por la que convocaba el Concilio Vaticano II, insistía en la exigencia que la iglesia tenía de renovarse para inyectar nueva sabia en el mundo. He aquí sus palabras: "La Iglesia asiste en nuestros días a una grave crisis de la humanidad, que traerá consigo profundas mutaciones. Un orden nuevo se está gestando, y la Iglesia tiene ante sí misiones inmensas, como en las épocas más trágicas de la historia. Porque lo que se exige hoy de la Iglesia es que infunda en las venas de la humanidad actual la virtud perenne, vital y divina del Evangelio." Y constataba el Papa: "El progreso espiritual del hombre contemporáneo no ha seguido los pasos del progreso material" (2).

Estas afirmaciones, que eran una auténtica profecía, se ven confirmadas hoy por todas partes. El corazón del hombre y de los pueblos se halla inquieto ante la quiebra existente entre el progreso material y el progreso espiritual. Los procesos de la globalización tanto en el campo económico como de la comunicación, están produciendo los fenómenos inquietantes de la exclusión, de los flujos migratorios, de propiciar la mentira y el oportunismo como reglas de conducta, con lo 
cual se mina desde el interior la misma relación humana, esa confianza sin la cual no puede subsistir la vida fraterna. Sin verdad e interioridad, nunca se desarrollarán relaciones justas y fraternas.

Esta quiebra cultural, que la sicología tipifica como desdoblamiento de la personalidad, nos alcanza también de lleno a los eclesiásticos. No podemos llevarnos a engaño; y conviene dejar constancia de ello, pues venimos del mundo y nuestras reacciones están influenciadas por la mentalidad reinante. El mundo está dentro de nosotros. Los grandes reformadores españoles, como san Juan de Ávila o santa Teresa de Ávila fueron muy lúcidos en este punto.

Pero de esta quiebra cultural emerge la añoranza difusa y el deseo de una búsqueda de sentido. Los hombres y mujeres de nuestro tiempo se interrogan de nuevo por el futuro y el camino a seguir para lograr una plena realización. Y ahí se enmarca la pregunta lanzada por el Papa Juan Pablo II en su programa pastoral para el s. XXI: ¿No es acaso un "signo de los tiempos" el que hoy, a pesar de los vastos procesos de secularización, se detecte una difusa exigencia de espiritualidad, que en gran parte se manifiesta precisamente en una renovada necesidad de orar? ¿Cómo responder a esta difusa exigencia de espiritualidad si nosotros, los pastores, no vivimos una profunda y recia espiritualidad? ¿Cómo contagiar la fe -y no sólo transmitirla de forma fría- sin una profunda vivencia de ella? ¿Cómo propiciar una experiencia de Dios, un encuentro vivo con Jesucristo, si no estamos enraizados en el Evangelio? ¿Cómo ser ministros de reconciliación en nuestro mundo sin una profunda espiritualidad de comunión?

El Papa hace referencia a los vastos procesos de secularización. Estos procesos, en efecto, han socavado muchas de nuestras prácticas religiosas, pero también son una oportunidad para una fe más despojada y libre de los lastres del pasado. Las crisis siempre contribuyeron a la emergencia de hombres y mujeres animadas por el Espíritu, que fueron una auténtica primavera para la Iglesia. Hoy, en nuestra sociedad secular, democrática y plural, hay indicios de un nuevo punto de partida. Pero esto supone que, personal y colectivamente, los pastores y las comunidades apuestan por la interioridad, a fin de que María y Marta, como diría santa Teresa, vuelvan a caminar juntas en nosotros. La escucha de la Palabra debe orientar tanto nuestra acción evangelizadora como nuestro servicio a los últimos. 
La urgencia misionera fundamenta, pues, la urgencia de una espiritualidad en el clero. Si no estamos enraizados en Cristo nuestros resultados terminan por ser frutos caducos y pereceros. Nuestro mundo vuelve a sentir hambre y sed de interioridad, de oración y espiritualidad.

\section{Hambre y ser de la Palabra}

Este signo de los tiempos recuerda la profecía que Amós pronunciara ante la vida corrompida de las ciudades, las injusticias sociales, la falsa seguridad que se pone en ritos, pero donde la persona no se compromete.

He aquí que vienen días - oráculo del Señor Yahvé-en que yo mandaré hambre a la tierra, no hambre de pan, ni sed de agua, sino de oír la Palabra de Yahvé. Entonces vagarán de mar a mar, de norte a levante andarán errantes en busca de la Palabra de Yahvé, pero no la encontrarán $(8,11-12)$.

La sed y el hambre de conocer la Palabra de Dios tiene que ver con la llegada de los tiempos mesiánicos y con la misión del sacerdote, tal como los profetas no dejaron de insistir. (Cf. Mt 5, 6; Dt 8, 3; Is 55, 6-7; Sal 145, 18; Os 5, 1-7; Is 11, 1-9; Hab 2, 14; Jr 31, 31-34; Núm $14,21 \mathrm{~s} ;$ Os 4, 4-10).

Para escrutar un signo de los tiempos es necesario, ante todo, renovar nuestra mirada de fe, tal como el Papa Juan XXIII en la citada Constitución Apostólica. Ante algunos espíritus que sólo veían negatividad a su alrededor, afirmaba el Papa con sencillez y frescura de alma: "Siguiendo la recomendación de Jesús cuando nos exhorta a distinguir claramente los signos... de los tiempos (Mt 16, 3), Nos creemos vislumbrar, en medio de tantas tinieblas, no pocos indicios que nos hacen concebir esperanzas de tiempos mejores para la Iglesia y la humanidad".

En una sociedad que valora los testigos, pero que desconfía de la palabra y tiene especial dificultad para aceptar cualquier tipo de magisterio, es preciso que los sacerdotes seamos auténticos familiares de la Palabra de Dios para ofrecerla con sencillez y transparencia al hombre contemporáneo. Es preciso dar razón de nuestra fe y de nuestra esperanza. Cierto, la caridad es importante, pero el hombre de hoy tiene 
ante todo hambre y sed de Dios, aunque trate de resolver la cuestión por caminos ajenos a la Iglesia.

Se ha comparado al hombre secular con el hijo pródigo. Éste, animado por el deseo de libertad y autonomía, se alejó de la casa paterna; pero después de una experiencia dolorosa, siente nostalgia de ella, entra dentro de sí e inicia el regreso al Padre. Pero este hombre secular necesita un guía para el regreso, pues le asalta una doble tentación: o bien buscar soluciones a su nostalgia en ciertas espiritualidades esotéricas y evasivas del mundo, o bien volver como un jornalero a la casa del Padre, renegando de su libertad filial. Ahí están como botones de muestra de la primera tentación la aparición de tantas sectas. Como expresión de la segunda tentación, baste citar los diversos fundamentalismos que atraviesan nuestra sociedad. Nuestro mundo necesita pastores y guías que sepan orientar la vuelta del hombre secular a la casa del Padre. Y esto no lo podrán hacer sin una profunda experiencia del Dios y Padre de nuestro Señor Jesucristo.

\section{La situación dell clero}

Hoy, cuando deploramos situaciones tan dolorosas en el clero, aireadas no siempre de forma justa por los medios de comunicación, estamos llamados a otear hacia dónde quiere conducirnos el Señor. No se trata de cerrar los ojos ante la realidad ni de adoptar posturas defensivas, sino de avanzar" con esperanza en el dinamismo del Espíritu de la verdad y la libertad.

Realistas, esperanzados y comprometidos son los ojos de un corazón animado por la fe apostólica. El corazón creyente ama y se pone al servicio de la plenitud del otro, sin juzgar ni condenar. No niega las sombras que pueden envolver la vida de personas o colectivos, como el eclesiástico, pero trabaja por disiparlas desde la solidaridad y comunión eclesial. ¿No lo recuerda así la vida de san Juan de Ávila? Gran conocedor de la miseria del clero de su tiempo, dedicó su vida a la renovación del mismo. Sufrió persecución y cárcel injusta, como lo atestigua el proceso que le abriera la Inquisición, pero no vemos en él amargura, crispación y, mucho menos, ácida desafección por la Iglesia. Las sombras denunciadas en prelados y sacerdotes, lejos 
de minarle por dentro, le hicieron crecer en comunión y compromiso en favor del clero.

Ante el desolador panorama de lo eclesiásticos de su tiempo, propugnó la necesidad de formar al clero para la santidad y al servicio de la misión de la Iglesia en el mundo. No vela la solución en leyes y sanciones. sino en la intensa renovación espiritual; sólo ella permitiría dar respuesta a los males de la Iglesia y a la necesidades de los débiles y pobres. Escuchemos lo que escribía en su primer memorial al Concilio de Trento, el cual había ya dictado algunas normas para los eclesiásticos. "Si quiere, pues, el sacro Concilio que se cumplan sus buenas leyes y las pasadas, tome trabajo, aunque sea grande, para hacer que los eclesiásticos sean tales, que more en ellos la gracia de la virtud de Jesucristo, lo cual alcanzado fácilmente cumplirán lo mandado, y aun harán más por amor que la Ley manda por fuerza. Mas aquí es el trabajo y la hora del parto, y donde yo temo nuestros pecados y la tibieza de los mayores: que, como hacer buenos hombres es negocio de muy gran trabajo, y los mayores, o no tienen ciencia para guiar esta danza, o caridad para sufrir cosa tan prolija y molesta a sus personas y haciendas, conténtanse con decir a sus inferiores: "Sed buenos, y si no, pagármelo heis", y no entienden en ayudarles a serlo. Porque el mandar es cosa fácil, y sin caridad se puede hacer; mas llevar a cuesta flaquezas ajenas con perseverante corazón de remediarlas y hacer fuerte al que era flaco pide riqueza de caridad".

Sin una espiritualidad honda y recia, los sacerdotes podemos vivir o una especie de depresión colectiva o bien una retirada a los cuarteles de invierno, al estilo de los discípulos de Emaús: sólo el encuentro y el reconocimiento del Resucitado nos devolverán a la comunión y a la misión. En efecto, aquellos hombres marchaban tristes, desencantados y cansados. El encuentro con el Resucitado les hizo regresar a la comunidad de Jerusalén para la misión.

\section{Conclusión}

La difusa exigencia de espiritualidad, que encontramos en nuestro mundo, se hace clamorosa necesidad cuando se trata de nosotros los pastores; y esto por un triple motivo: El mundo secular necesita 
guías experimentados en la experiencia de Dios; los problemas del clero no se resolverán por leyes y normas, sino por una profunda experiencia del Resucitado, a cuya realización deben colaborar las normas y leyes; para que el hombre de hoy acepte la autoridad de la revelación, es preciso que vea cómo la Palabra de Dios es capaz de hacer de sus testigos hombres de esperanza y alegría. ¿De qué serviría repetir principios justos y certeros si no conducimos a los hombres al encuentro con Dios, a que concedan a la palabra de la revelación plena autoridad en sus vidas? Hoy no basta con transmitir de forma objetiva la fe, es preciso que los pastores la contagiemos realmente. Sólo así, el sujeto libre recibirá la fe apostólica en su integridad y objetividad; y sólo quien viva una profunda espiritualidad será capaz de ofrecer la te de la Iglesia en su verdad y novedad sin ocaso.

La necesidad de espiritualidad es clara, pero surge una segunda cuestión: ¿Qué tipo de espiritualidad necesitamos hoy los sacerdotes? En este punto, dada la fecha y, ocasión de esta intervención, he pensado que lo mejor era evocar algunas de las afirmaciones de san Juan de Ávila y tratar de actualizarlas para nosotros. No olvidemos que fue la de "San Pedro Apóstol de presbíteros naturales de Madrid", en 105 años 1623-1625, la primera; en promover la causa de su canonización.

\section{II.- RASGOS DE UNA ESPIRITUALIDAD APOSTÓLICA}

\section{La fe en el amor}

San Juan de Ávila vivió en tiempo de cristiandad. No había que dar 'razón de la fe' como en nuestros días, pero no faltaban los descreídos e incrédulos, incluso en el clero. Veía el santo que no se creía bastante en el amor del Padre y del Hijo, por lo cual escribió el Tratado del amor de Dios. En este amor se encuentra la explicación última del mismo sacerdocio de Cristo y de sus ministros. El pastor que no cree en el amor no podrá vivir su ministerio con alegría y gratuidad.

La experiencia de ser amado refluye en amor a Dios y a los hombres. Y cuanto mayor es la experiencia del amor divino, más es la entrega al servicio de los hombres. El apóstol de Andalucía expresó con gran belleza esta dinámica del amor. Después de establecer que el amor de 
Cristo es comunión con el amor del Padre por los hombres, escribía: "Pues si aquel amor del alma de Cristo para con Dios llevaba tan admirable fuerza (porque la pólvora de la gracia que le impelía era infinita) cuando, después de haber ido derechamente a herir en el corazón del Padre, resurtiese de allí al amor de los hombres, ¿con cuánta fuerza y alegría volvería sobre ellos para amarlos y remediarlos?"

La fe en el amor es el inicio de una auténtica espiritualidad sacerdotal. Pero esta experiencia debe ser cultivada de modo incesante en la plegaria, en los sacramentos, en el encuentro con los hermanos. Es la fuente de la verdadera alegría y entrega sacerdotal. La fe se traduce en una existencia para los demás. Quien vive enraizado en el amor, como Pablo, vive con auténtica pasión la misión de formar a Cristo en la comunidad (Cf. Gál 4, 19-20).

Hoy estamos llamados a dar razón de nuestra fe en medio del mundo. Hoy estamos urgidos a conducir a los hombres a la experiencia auténtica del amor del Padre tal como se ha revelado en Cristo. Hoy estamos apremiados a renovarnos en aquellas palabras de la fe apostólica: "Nosotros hemos conocido el amor que Dios nos tiene, y hemos creído en él. Dios es amor y quien permanece en el amor permanece en Dios y Dios en él" (1 Jn 4, 16) Sólo el amor da alas para vivir con audacia e intensidad el riesgo de la misión. El sacerdote, siguiendo la expresión de nuestro patrono, o es "un amador" o su vida será un fracaso total ante Dios y ante los hombres.

\section{La conciencia del don de Dios}

Juan de Ávila tenía una aguda percepción de la gracia del ministerio sacerdotal. Profundamente enraizado en el sacramento de la fe, la Eucaristía descubre la dignidad sacerdotal en su luz. El sacerdocio es un don inmerecido. Ninguna realidad en el mundo puede compararse con él. Se complace en compararlo con la Virgen y con los mismos ángeles, para insistir que en algunos aspectos les sobrepuja.

Pero la dignidad sacerdotal proveniente de la Eucaristía, se convierte en una crítica lúcida y penetrante, pero siempre cordial, para las formas mundanas de desarrollar el sacerdocio. El ministro de la Eucaristía debe hacerse uno con el Señor, el cual vivió en pobreza y humil- 
dad, desasido de sí y entregado al servicio de todos. El corazón y la casa del pastor debe estar abierta a los pobres y desvalidos.

La grandeza del servicio eucarístico conlleva una exigencia radical de santidad Su teología del sacerdocio partía del poder de celebrar la Eucaristía. Su espiritualidad seguía la dinámica profunda del misterio de la fe. La Eucaristía era fuente de la caridad pastoral y exigencia suprema de santidad para el sacerdote. El Concilio Vaticano II y el Magisterio posterior siguen insistiendo en la misma perspectiva.

Cierto, la Eucaristía debe estructurar la acción y espiritualidad del ministro del Evangelio. Hacia ella debe tender toda su acción misionera y de ella deben brotar todas sus iniciativas apostólicas. El Padre nos sigue enviando a los caminos para convocar a todos al banquete del Reino, en particular los excluidos y alejados.

Puesto que estamos ante un don de Dios, el sacerdote debe ser un hombre eucarístico, es decir, alguien que vive la existencia desde la acción de gracias, pues se siente agraciado. Pero la elección es para el servicio y crecimiento de la comunidad, jamás para servirse de ella o dominarla. Se trata de unirse a Cristo para ser con el buen pan para los demás. El sacerdote está llamado a servir la doble mesa de la Palabra y de la Eucaristía para alimentar a los peregrinos del Reino. ¿No nos hallamos ante un criterio decisivo para verificar la verdad de nuestras vidas ministeriales y también para discernir las vocaciones sacerdotales? Dar razón de nuestro sacerdocio en el mundo y en la comunidad, pues, no es otra cosa que vivir en la dinámica del sacramento del amor, que es la Eucaristía.

\section{La docilidad al Espíritu Santo}

El Maestro Ávila no tiene el lenguaje de los signos de los tiempos, pero vivió su dinámica con hondura. En efecto, prestó gran atención a las reacciones de la gente sencilla; y concedió una importancia capital a descubrir y secundar con docilidad la acción del Espíritu en su situación.

Fue un hombre de la gran Tradición de la Iglesia. En su obra cita con frecuencia las Escrituras, Concilios, Sínodos y Padres de la Iglesia. Buscó en el pasado inspiración para sus iniciativas. Pero sabía tam- 
bién que la repetición se podía convertir en clara oposición al Espíritu y a la Iglesia. Los que no vivían en una sana dinámica de conversión y reforma, se escudaban en la costumbre, para mantener una vida en clara oposición al Evangelio. ¿No fue una de las razones por la que se vio a vueltas con la Inquisición?

Como portador del "ministerio del Espíritu", el pastor está 1lamado a ser un auténtico colaborador suyo. Pero esto supone que en la presidencia de los sacramentos, en el anuncio de la fe apostólica, en el encuentro con las personas, en las relaciones dentro de la Iglesia, avanza siempre en perfecta docilidad y sintonía con el Espíritu. Si Él nos precede en el corazón de las personas y de los pueblos, necesario será que nuestra pastoral asuma la forma de la contemplación y del discernimiento en el seno de la comunión eclesial. Si el Espíritu nos hace entrar en la verdad y novedad plenas del plan de Dios, menester será que la interioridad de la escucha preceda nuestras palabras. Si el Espíritu edifica la comunión en la diversidad, nadie puede adoptar posturas de exclusión o de autoexclusión.

La docilidad al Espíritu, en este momento de la historia del mundo, se hace particularmente urgente. La nueva evangelización y la transmisión de la fe, en mi opinión, pasa por un serio trabajo de discernimiento de los sacerdotes con el Obispo a la cabeza. Es preciso acoger en los gritos de los pobres, en la vivencia de nuestras comunidades e incluso en las críticas de quienes son hostiles a la Iglesia, la palabra que Dios nos dirige, para ponerla en práctica. El Espíritu nos precede en el corazón de las personas y de la historia. Es, a mi juicio, un camino decisivo para recuperar la pasión y esperanza apostólicas, únicas capaces de dar dinamismo a nuestros útiles y necesarios planes pastorales.

\section{Una espiritualidad eclesial, de comunión}

Insisto. La repetición y añoranza del pasado no es sinónimo de fidelidad al Espíritu. La Novedad perenne de Dios y los cambios de nuestro mundo exigen de los pastores, puestos por el Espíritu Santo al frente de la Iglesia, que sean dóciles a su creatividad y libertad. La fidelidad creativa, lo sabía bien Juan de Ávila, es la garantía de caminar en aquella comunión eclesial, que el Espíritu no cesa de alentar. 
Si queremos "hacer de la Iglesia la casa y la escuela de la comunión", si queremos "promover una espiritualidad de la comunión", si queremos promover "espacios de comunión" (TMI 4345) y diálogo -tanto en la comunidad eclesial como en las comunidad humana- los pastores del Pueblo de Dios debemos trabajar con ahínco para desarrollar nuestra vocación de ministros de unidad y reconciliación.

La comunión eclesial no era algo optativo o negociable para el Maestro Ávila; pero también es claro, en sus escritos y vida, que la denunció como falsa cuando faltaba la dinámica de la verdad, libertad, conversión y del amor fraterno. El Espíritu de comunión es, al mismo tiempo, el Espíritu de la verdad, de la libertad y del amor.

Una espiritualidad de comunión es muy exigente, pues sería mal vivida por las personas y grupos que tratasen de imponer sus proyectos y criterios, sin discernir y acoger los variados dones del Espíritu, sin poner a los pobres en el centro de la comunión, sin vivir una real interdependencia y corresponsabilidad en la misión. Cierto, una crítica ácida y sin amor impide la comunión, pero se olvida que es más perniciosa la actitud de quienes se sitúan como autosuficientes y jueces de los demás, o bien los que se repliegan sobre sí mismos con una clara desafección a la Iglesia.

Por otra parte, el servicio de la unidad y comunión, exige de los pastores una auténtica mística de la Iglesia particular y del presbiterio con el Obispo al frente. La comunión presbiteral es fraternidad y acción conjunta al servicio de la totalidad del Pueblo de Dios. La unidad de vida y acción se encaminan a que el mundo crea que Jesucristo es el Enviado del Padre.

\section{La oración como ministerio y servicio al pueblo de Dios}

La insistencia en la oración es una característica decisiva en la espiritualidad sacerdotal del Maestro Ávila. Sin interioridad no hay espacio para el encuentro, escucha y comunión con el Señor. Sin contemplación, el discernimiento queda reducido a un juicio de hechos y personas a partir de sus propios presupuestos; no hay espacio para la conversión del corazón y de la acción. El primado de la gracia puede quedar empañado. Sí, san Juan de Ávila veía que la oración personal 
era el camino para que los ministros del Señor vivieran en una auténtica dinámica de conversión su sacerdocio.

Pero el santo no veía la oración tan sólo como una ayuda para ser mejor sacerdote. Defendía que para los sacerdotes era el ejercicio mismo de su ministerio. Partícipe de la mediación de Cristo, el sacerdote debía desarrollar el inmenso "privilegio de la intercesión", por usar una expresión del Cardenal Newman, como su actividad primordial en favor del pueblo. Evocaba así Juan de Ávila la propuesta de los Doce a la asamblea de los discípulos: "No parece bien que nosotros abandonemos la Palabra de Dios por servir a las mesas. Por tanto, hermanos, buscad de entre vosotros a siete hombres, de buena fama, llenos de Espíritu y de sabiduría, y los pondremos al frente de este cargo; mientras que nosotros nos dedicaremos a la oración y al ministerio de la Palabra" (Hech 6, 1-7). Y la propuesta pareció bien a toda la asamblea.

En efecto, uno de los grandes desafíos para la Iglesia fue siempre la inculturación de la fe y de la vida evangélica. Ahora bien, esto es imposible sin un estudio y oración asidua de las Escrituras. Cuando el activismo pastoral y social se impone en la vida de los pastores, la predicación de la Buena Nueva de Jesucristo y del Reino de Dios tiende a reducirse a un mero programa de moral. La identidad cristiana se desdibuja y diluye.

Conscientes de lo que nos traemos entre manos, es preciso que los ministros del Evangelio recuperemos la práctica de la Lectio Divina, pero ante todo el sentido de la oración. Esta es constitutiva de nuestro ser y hacer ministerial; y no sólo una exigencia para ser buenos sacerdotes. Estar con Cristo y seguirlo, funda la existencia apostólica. En ella ejerce el pastor su ministerio de vigilancia e intercesión en favor del pueblo. Es también acción indispensable para acoger la Palabra de Dios que debe comunicar a los hombres de su tiempo.

Esta oración, por tanto, exige del pastor una presencia atenta, vigilante y comprometida en la vida de los hombres. Es un camino para conocer a las ovejas en Dios y para conocer la palabra que debe transmitirles. En el corazón del pastor deben darse cita Dios y el mundo de los hombres. Tal fue la oración de Jesús y de los pastores según Dios. 


\section{La radicalidad evangélica}

Enraizado en el amor de Cristo y en la fe de la Iglesia, san Juan de Ávila no dudó de proponer al clero de su tiempo un camino de radicalidad evangélica. ¿Estaba aquel clero preparado para escuchar semejante mensaje? Sinceramente no, pero el santo creía en la fuerza de la gracia y de la verdad del Evangelio. Hoy también estamos llamados a vivir esta misma confianza en la fuerza del Espíritu. No podemos proponer una espiritualidad de rebajas.

El camino del amor, de la caridad pastoral, una entrega libre e incondicional a la edificación de la comunidad de la Alianza del Espíritu. El amor reclama una libertad siempre mayor para la misión. Y fue la caridad pastoral, la que llevó a Juan de Ávila a predicar pobreza y amor a los pobres, a un clero que vivía en la lógica y estatus de los señores feudales. En sus memoriales y advertencias el santo descendía a detalles muy concretos, como era la forma de vestir, de comer, de dormir. Con fuerza insistía, por ejemplo, en que las casas de los prelados y sacerdotes estuvieran abiertas a los pobres.

Ante una vivencia desastrosa de la castidad por parte del clero, el santo no cesó de predicar la importancia del celibato, como una exigencia del amor a Dios y a su pueblo. No se limitó a recordar una regla, sino que tomó la cuestión en su hondura.

A sus ojos, la obediencia y docilidad al Espíritu de Dios era el fundamento último de toda espiritualidad. En efecto, el sacerdote como representante del Buen Pastor debe vivir en su comunión y dependencia. Y esto a través de las mediaciones establecidas por el mismo Señor. Pero esta obediencia, como lo afirmó de forma magistral el Concilio Vaticano II, en modo alguno es servilismo. El verdadero pastor sabe que la obediencia de fe es una apuesta por el servicio responsable al Pueblo de Dios.

El camino del amor, en su radicalidad, adquiere para san Juan de Ávila la forma de la obediencia, pobreza y castidad en el celibato. Forman como un todo inseparable en su pensamiento y vida. Quien busca riqueza, pronto abandonará el camino del servicio gratuito y de la castidad, así como de la obediencia. Quien se aparta de su estado célibe, buscará poseer y caminar por libre. Quien no avance en la obediencia adulta y madura al Señor en la Iglesia, correrá detrás de sus propios proyectos y afectos. 


\section{Conclusión}

En resumen, san Juan de Ávila propugnó una espiritualidad apostólica, es decir, la vida según los apóstoles. Una vida de intensa fe, alimentada de forma ininterrumpida en la oración y los sacramentos de la Iglesia. Una vida de amor hasta el extremo en la lógica y dinámica de la Eucaristía. Una vida de estudio, acción y trabajo para servir al hombre en su totalidad, en particular a los débiles y los pobres. Este es el camino que le dio a entender el Espíritu para contribuir con verdad y dolor a la reforma de la Iglesia.

La fidelidad a san Juan de Ávila, obliga a proceder con realismo y temple. Buscó y puso en obra medios concretos para llevar a cabo la reforma. No creía que los decretos y leyes, aunque útiles y necesarios, fueran la respuesta a los males de la Iglesia y del clero, pero no dejó de tomar iniciativas para crear y propugnar cauces aptos para forjar sacerdotes según el corazón de Dios. Hoy nos toca a nosotros hacer lo mismo. Por ello quiero sugerir ahora algunas propuestas, no nuevas, ciertamente, pero que deben ser recreadas en función de las personas y situaciones.

\section{PROPUESTAS}

\section{Formación permanente}

Como en tiempos de san Juan de Ávila, uno de los retos para el clero es la formación permanente. Se lamentaba el santo del fracaso de ciertos decretos conciliares, pues sus prescripciones o no se habían acogido o no se les daba la orientación conveniente. Quizá nos esté pasando lo mismo a nosotros.

Hoy, a mi entender, sería importante organizar una Formación Permanente en la perspectiva de lo que se dice en la Exhortación Apostólica Pastores Dabo Vobis. Una formación que armonice la dimensión pastoral, litúrgica y teológica en orden a desarrollar una auténtica mística del ser y del hacer ministerial. La Formación Permanente es muy diferente a una información o a unos cursos.

Por otra parte, debería convertirse en una auténtica escuela de oración apostólica y discernimiento, adaptada a la edad de los sacer- 
dotes y a su situación pastoral. Si no responde a necesidades vitales de los ministros aparecerá como una carga más, añadida a nuestras muchas actividades. Los procesos de formación debe ser un lugar de unificación de la persona del sacerdote en torno a su acción pastoral.

El Catecismo de la Iglesia Católica, en el artículo Maestros y lugares de oración, afirma: "En la confluencia de corrientes litúrgicas y teológicas se encuentra también una espiritualidad que muestra cómo el espíritu de oración incultura la fe en un ámbito humano y en su historia. Las diversas espiritualidades cristianas participan en la tradición viva de la oración y son guías indispensables para los fieles" (2684). En esta perspectiva, la Formación Permanente debe contribuir a ese trabajo serio, paciente e inteligente que conlleva la inculturación de la fe; condición indispensable para llevar a cabo su transmisión en un mundo que experimenta un profundo cambio cultural.

\section{Fraternidades sacerdotales}

El Concilio Vaticano II afirmó la fraternidad sacerdotal como una exigencia intrínseca del sacerdocio ministerial. Esta afirmación necesita cauces concretos para que sea hecha vida y contribuya a la evangelización del mundo.

San Juan de Ávila no cesó de trabajar para que los sacerdotes, en continuidad con las iniciativas de san Agustín, pudieran vivir un cierto tipo de comunidad sacerdotal. El célibe necesita espacios de encuentro humano, de diálogo pastoral, de oración y discernimiento. Sin ellos, corre el riesgo de cerrarse sobre sí mismo o de evadirse en la actividad. Más, sin el estímulo de la vida fraterna las exigencias de la caridad pastoral, como pueden ser la pobreza y la castidad en el celibato, sufren más fácilmente detrimento.

Tengo la convicción profunda de que sin fraternidades sacerdotales resulta muy difícil vivir la dinámica de la conversión permanente que entraña una vida de discípulo. Debemos comprometernos todos para buscar y poner en práctica caminos y medios que permitan avanzar en este sentido.

Las relaciones fraternas entre sacerdotes, no pueden reducirse a la organización funcional de las tareas pastorales. Somos infinitamente 
más que meros funcionarios de una organización religiosa. Es urgente, en mi opinión, imaginar y propiciar con realismo nuevas formas de vida fraterna entre los presbíteros. La recepción del Concilio Vaticano II incluye iniciativas en este sentido: "A fin que los presbiteros se presten mutua ayuda en el cultivo de la vida espiritual e intelectual, puedan cooperar más adecuadamente en el ministerio y se libren de los peligrosa que acaso se originen de la soledad, foméntese entre ellos alguna manera de vida común o alguna convivencia, que puede, sin embargo, revestir muchas formas, según las distintas necesidades personales o pastorales, a saber, la convivencia, donde fuere posible, o la mesa común o, por lo menos, las reuniones frecuentes y periódicas" (PO 8).

\section{Grupos de oración en torna a la Palabra}

Además de los ejercicios y retiros que se organizan a nivel diocesano o de Vicarias, juzgo muy importante la formación de grupos sacerdotales de oración en torno a la Palabra de Dios. Estos grupos deben caracterizarse por la gratuidad y la confianza mutua. Su finalidad no sería buscar soluciones a las cuestiones pastorales, pues para ello deben existir otros cauces, sino impulsar la condición de oyente y discípulo de la Palabra hecha carne.

Deben ser grupos abiertos y creados con libertad. En este punto cualquier imposición los haría inoperantes. Pero tampoco la amistad puede constituir el único criterio para su formación, si realmente quieren tener futuro. Evitarán, por todos los medios, convertirse en grupos de presión o alternativos. La diócesis, en la medida, que lo desearan podría ofrecer pistas de trabajo y ayuda.

Estos grupos serían espacios muy aptos para la práctica del discernimiento espiritual, del cual estamos tan necesitados los presbíteros. La riqueza de estos grupos se proyectaría pronto en la vida de las comunidades parroquiales y de todo tipo de movimientos e instituciones eclesiales.

San Juan de Ávila contribuyó de forma decisiva a la formación de una auténtica escuela y espiritualidad sacerdotal. Estos grupos pueden ser como los viveros de donde surjan nuevas iniciativas en orden a promover vocaciones sacerdotales y para la vida consagrada. Pero para 
iniciar esta andadura se necesita un núcleo de presbíteros decididos a desarrollar la entraña comunitaria del ministerio sacerdotal.

\section{Diferentes espiritualidad en el presbiterio}

"En la comunión de los santos, se han desarrollado diversas espiritualidades a lo largo de la historia de la Iglesia. El carisma personal de un testigo del amor de Dios hacia los hombres puede transmitirse a fin de que sus discípulos, participen de ese mismo espiritu (Cf PC 2), como aconteció con el 'espíritu' de Elías a Elíseo (Cf $2 R 2$ 2, 9) y a Juan Bautista (Cf Lc 1, 17)" (CIC 26984). Esto es válido igualmente cuando se trata de los diferentes caminos que los presbíteros pueden seguir para responder con fidelidad y creatividad a la vocación apostólica. La Iglesia, como lo demuestra la escuela avilista, defendió siempre la legitimidad de desarrollar la vocación a la santidad por diferentes caminos.

Pero no deben olvidar los grupos, que se inspiran en diferentes corrientes de espiritualidad, el sentir de la Iglesia sobre ellos. Dios lo suscita para que sirvan a los otros presbíteros, para que fomenten la fraternidad entre todos, para que se dejen enriquecer por los dones y carismas de los demás hermanos, para que bajo la guía del Obispo, y nunca al margen de él, se impliquen en la búsqueda de nuevas iniciativas pastorales. ¿No exige una auténtica espiritualidad de comunión que todos trabajemos juntos a edificar el presbiterio diocesano?

\section{Cauces institucionales de diálogo}

Quiero insistir, por último, en la necesidad de aprovechar los cauces existentes de diálogo y de promover aquellos que se juzguen oportunos. En una cultura marcada pos las leyes de la competencia y, en consecuencia, del mutuo recelo, los presbíteros debemos ser testigos de diálogo, amistad y solidaridad y gratuidad. La vocación y misión sacerdotal es comunitaria. Nadie es sacerdote por libre, pues la llamada del Señor ratificada por la ordenación sacerdotal nos introdujo en el presbiterio. Seamos responsables unos de otros, pues la fidelidad del hermano hace posible la mía y viceversa. 


\section{Conclusión}

El término espiritualidad es de cuño relativamente reciente, pero el vivir en el Espíritu es de siempre. Espiritual es el hombre que vive bajo la moción del Espíritu. Y la espiritualidad será siempre un camino que nos lleve a caminar en el Espíritu para producir los frutos abundantes y perennes de la Vid verdadera.

San Pablo, escribiendo a los Gálatas, perturbados en su fe por los falsos hermanos infiltrados en la comunidad, afirmaba al final de su carta: "Si vivimos según el Espíritu, obremos también según el Espíritu” (Gál 5, 26).

Como eco de esta palabra apostólica resuena la afirmación de san Basilio: "El Espíritu es verdaderamente el lugar de los santos, y el santo es para el Espíritu un lugar propio, ya que se ofrece a habitar con Dios y es llamado templo suyo" (Spir. 26, 62).

Concluyo estas reflexiones, ya que nos encontramos en los días previos a Pentecostés, con una oración de san Juan de Ávila: "Plegue al Espíritu Santo, por los merecimientos de Jesucristo, y por aquella sangre que derramó en la cruz por nosotros, tenga por bien venir en nuestros corazones y sanar nuestras almas, alumbrar nuestros entendimientos, para que conozcamos a Dios, y enderezar nuestra voluntad para solamente amar a Dios y olvidarse de las cosas del suelo, y sujetar nuestra carne, y darnos humildad, castidad y caridad para con nuestros prójimos, y damos sus siete dones, para que, teniendo su gracia, nos dé la gloria" (Juan de Ávila, Escritos sacerdotales, p. 288). 